\title{
Bile acid and lysolecithin concentrations in the stomach in patients with duodenal ulcer before operation and after treatment by highly selective vagotomy, partial gastrectomy, or truncal vagotomy and drainage
}

\author{
P DEWAR, ${ }^{*} \mathrm{R}$ KING, and D JOHNSTON \\ From the University Department of Surgery, The General Infirmary, Leeds
}

SUMmARY Duodenogastric reflux of bile acids and lysolecithin in the course of a standard test meal was measured in normal people and in patients with duodenal ulcer before operation and more than one year after highly selective vagotomy, Polya partial gastrectomy, truncal vagotomy and pyloroplasty, and truncal vagotomy and gastrojejunostomy. Before operation, duodenal ulcer patients had significantly higher fasting, post-prandial, and peak bile acid concentrations in the stomach than had normal subjects. After Polya partial gastrectomy, fasting, post-prandial, and peak concentrations of bile acids and lysolecithin were significantly higher than in preoperative duodenal ulcer patients. After highly selective vagotomy, in contrast, bile acid concentrations in the stomach were significantly lower than in preoperative duodenal ulcer patients and post-prandial and peak lysolecithin concentrations were less than half (NS) those recorded in preoperative duodenal ulcer patients. After highly selective vagotomy, bile acid concentrations were also significantly lower than bile acid concentrations after Polya partial gastrectomy, truncal vagotomy and pyloroplasty, and truncal vagotomy and gastrojejunostomy; and post-prandial and peak lysolecithin concentrations were significantly lower than after Polya partial gastrectomy and truncal vagotomy and gastrojejunostomy. Thus, when used in the treatment of patients with duodenal ulcer, highly selective vagotomy keeps 'bile' out of the stomach, probably through its effect on gastric smooth muscle, combined with the preservation of an intact antropyloroduodenal segment. In contrast, Polya partial gastrectomy, truncal vagotomy and gastrojejunostomy, and truncal vagotomy and pyloroplasty all lead to a significant increase in reflux of bile acids and lysolecithin into the stomach. The clinical importance of these findings is that both gastritis and, in the long term, gastric carcinoma may prove to be less common after highly selective vagotomy than after partial gastrectomy or vagotomy with a drainage procedure.

Traditional operative procedures for duodenal ulcer such as partial gastrectomy and vagotomy with a drainage procedure are known to increase duodenogastric reflux. ${ }^{1}$ Duodenal content in the stomach breaks the gastric mucosal barrier by its detergent action and, with or without the aid of acid, pepsin, and agents such as aspirin or alcohol, produces a chronic gastric mucosal reaction or gastritis. ${ }^{2-4}$ Such 'bile reflux gastritis' may produce symptoms such as

\footnotetext{
* Address for correspondence: Mr E P Dewar, Department of Surgery, Royal Naval Hospital, Haslar, Gosport, Hants PO12 2AA.

Received for publication 19 October 1981
}

epigastric pain, nausea, vomiting, and loss of weight $^{5-7}$ and, in the long term, there is an increased risk of gastric carcinoma. ${ }^{8-10}$

Highly selective vagotomy, unlike these procedures, preserves the pylorus ${ }^{11}$ and might thus be expected not to produce an increase in duodenogastric reflux. In this paper we show that, after highly selective vagotomy, reflux of bile acids and lysolecithin into the stomach is, in fact, significantly less than in patients with duodenal ulcer before operation. As expected, both partial gastrectomy and truncal vagotomy with a drainage procedure were followed by significant increases in duodenogastric reflux. 


\section{Methods}

\section{PATIENTS}

Six groups of patients were studied (Table 1). One group consisted of 16 patients with active duodenal ulceration who had not been operated upon. A second control group comprised nine normal subjects with no history of disease of the gastrointestinal tract. The other four groups consisted of patients who had been treated surgically for duodenal ulcer more than one year previously: 14 by highly selective vagotomy, 11 by Polya partial gastrectomy, nine by truncal vagotomy and Heineke-Mikulicz pyloroplasty, and eight by truncal vagotomy and gastrojejunostomy. The groups did not differ significantly with respect to age and sex. The mean interval between operation and these studies was four years in the highly selective vagotomy group, eight years in the truncal vagotomy and drainage groups, and 20 years in the Polya partial gastrectomy group. The results of operation were good (Visick grades 1 or 2$)^{12}$ in all these postoperative patients. The diagnosis of duodenal ulceration had been made in each patient by barium meal examination and/or fibreoptic endoscopy and had been confirmed at operation in each patient who had undergone surgery. The nature and purpose of the investigations were carefully explained to each patient and his or her consent obtained.

\section{FIBREOPTIC OESOPHAGOGASTRODUODENOSCOPY}

Each patient underwent this procedure, which was performed for diagnostic purposes in the preoperative duodenal ulcer patients and in the postoperative patients both to confirm that the ulcer had healed and to exclude the presence of any other pathological condition in the stomach and duodenum. At endoscopy the presence or absence of bile reflux was recorded and multiple gastric and duodenal biopsies were taken in each case to form the basis of a separate report on the morphological state of the gastric mucosa in relation to 'bile' reflux.
There was no evidence of gall bladder disease in any patient, either on oral cholecystography or at operation.

TEST MEAL AND SAMPLING TECHNIQUE

After the patient had fasted overnight, a size 12 nasogastric tube was positioned in the stomach using the water recovery method. ${ }^{13}$ Resting juice was aspirated and discarded. Three $8 \mathrm{ml}$ samples of gastric juice were collected by gentle suction with a syringe at 20 . minute intervals during the 'basal' hour. A standard Lundh test meal was then given. It consisted of $300 \mathrm{ml}$ of water containing $13.5 \mathrm{~g}$ protein, $18 \mathrm{~g}$ corn oil, and $53 \mathrm{~g}$ carbohydrate, and was ingested over a five minute period. A further four samples of gastric content were then collected at 20 minute intervals. The patient remained seated in a chair throughout the period of study. The procedure was well tolerated and none of the patients complained of nausea during the test.

The samples of gastric aspirate were placed in tubes containing $0.002 \mathrm{M}$ ethylenediaminetetracetic acid and $0.005 \mathrm{M}$ calcium chloride to inhibit phospholipase A activity. This prevented in vitro hydrolysis of lecithin to lysolecithin, a process catalysed by phospholipase $\mathrm{A}$ and activated by bile acids and trypsin. ${ }^{14}$

\section{MEASUREMENTS OF BILE ACIDS}

Concentrations of total bile acids were measured using a commercial kit (Sterognost $3 \propto^{\mathrm{R}}$-Pho. Nyegaard). ${ }^{15}$ The method depends on the activity of a non-specific $3 \propto$-hydroxysteroid dehydrogenase linked to the reduction of nicotinamide adenine dinucleotide $\left(\mathrm{NAD}^{+}\right)$. All $3 \propto$-hydroxysteroid bile acids, both free and conjugated, are converted to the corresponding 3-ketosteroids with the formation of nicotinamide adenine dinucleotide reduced (NADH).

Determinations were made in duplicate in a medium containing $0.0003 \mathrm{M} \mathrm{NAD}{ }^{+}, 0.082 \mathrm{M}$ hydrazine hydrate buffer, $\mathrm{pH} 9.5$ and $20 \mu$ l of gastric aspirate in a final volume of $1.52 \mathrm{ml}$. The reduction

Table 1 Details of patients

\begin{tabular}{|c|c|c|c|c|c|c|}
\hline \multirow[b]{2}{*}{ Group } & \multirow[b]{2}{*}{$n$} & \multicolumn{2}{|c|}{ Age (yr) } & \multirow{2}{*}{$\begin{array}{l}\text { Sex } \\
\text { (male) }\end{array}$} & \multicolumn{2}{|c|}{$\begin{array}{l}\text { Length of follow-up (yr) } \\
\text { after operation }\end{array}$} \\
\hline & & Mean & Range & & Mean & Range \\
\hline Control & 9 & $46 \cdot 4$ & $33-74$ & 6 & - & \\
\hline DU & 16 & $42 \cdot 0$ & $22-58$ & 11 & - & \\
\hline HSV & 14 & $50 \cdot 1$ & $30-68$ & 11 & $4 \cdot 4$ & $1-10$ \\
\hline $\mathrm{TV}+\mathrm{P}$ & 9 & $50 \cdot 5$ & $33-70$ & 6 & $7 \cdot 7$ & $3-13$ \\
\hline $\mathrm{TV}+\mathrm{GJ}$ & 8 & $57 \cdot 0$ & $44-74$ & 6 & $8 \cdot 4$ & $3-13$ \\
\hline
\end{tabular}


of $\mathrm{NAD}^{+}$was followed at $340 \mathrm{~nm}$ using a Pye Unicam SP 1800 dual beam spectrophotometer. The smallest detectable difference in bile acid concentration was governed by the sensitivity of the spectrophotometer. For the instrument used this was equivalent to $10 \mu \mathrm{mol} / \mathrm{l}$ of bile acid. The between assay coefficient of variation using this technique was $5 \%$.

Bile acid concentrations in each 20 minute period were used to calculate the mean bile acid concentrations (1) in the fasting state for one hour, and (2) after the meal for 80 minutes. These values were termed the mean fasting concentration and the mean post-prandial concentration, respectively. The mean peak concentration was calculated from the highest concentration of bile acid recorded in each patient.

\section{MEASUREMENT OF LYSOLECITHIN}

Phospholipids were extracted from $2 \mathrm{ml}$ of aspirate by the method of Bligh and Dyer. ${ }^{16}$ Samples of this extract $(4 \mathrm{ml})$ were evaporated under nitrogen, redissolved in a small quantity of chloroform, and applied to thin layer chromatographic plates of silica gel $\mathrm{H}$ (thickness $0.5 \mathrm{~mm}$ ) together with standards of lysolecithin. Plates were developed in chloroform/ methanol/water $(65: 25: 4 \text { by vol })^{17}$ and the separate lipid spots demonstrated by iodine vapour. Sample spots containing lysolecithin were scraped from the plate and assayed for phosphate after degradation. ${ }^{18}$ To each sample of silica gel was added $1.1 \mathrm{ml} 11.7 \mathrm{M}$ perchloric acid. This mixture was heated on a sandbath and maintained at a temperature of approximately $230^{\circ} \mathrm{C}$ to ensure digestion of the lipid. After cooling, the original volume of perchloric acid was restored by weight and the liberated phosphate was assayed using a colorimetric technique. ${ }^{19}$

Standards of free phosphate were used in the calculation of the amount of phosphate liberated by acid degradation but the efficiency of extraction of lysolecithin was determined by the addition of known quantities of pure lysolecithin to both low range and high range patient samples. In this way it was possible to quantify the loss of lysolecithin at all stages of the extraction. The overall recovery was found to be $45 \pm 5 \%$ (mean \pm 1 SD) and this included the losses on extraction, evaporation, transfer, thin layer chromatography, degradation, and assay. The fasting, post-prandial, and peak values of lysolecithin were calculated as for the bile acids.

\section{STATISTICAL METHODS}

The values reported represent the means of duplicate determinations on each sample plus or minus one standard error of the mean. The significance of differences between the groups was determined by means of the Wilcoxon rank sum test. ${ }^{20}$

\section{Results}

\section{BILE ACID CONCENTRATIONS IN STOMACH}

Bile acid concentrations in the stomach in the six groups of patients are shown in Figs. 1 and 2 and in Table 2.

Patients with duodenal ulcer, before operation, had significantly higher fasting, post-prandial, and peak bile acid concentrations in the stomach than did normal subjects.

In patients who had undergone highly selective vagotomy fasting, post-prandial, and peak bile acid

Table 2 Bile acid concentrations $\left(\mu \mathrm{mol} \mathrm{l}^{-1}\right)$

\begin{tabular}{|c|c|c|c|c|c|c|}
\hline Group & Fasting & $\begin{array}{l}\text { Significance } \\
\text { of difference }\end{array}$ & $\begin{array}{l}\text { Post- } \\
\text { prandial }\end{array}$ & $\begin{array}{l}\text { Significance } \\
\text { of difference }\end{array}$ & Peak & $\begin{array}{l}\text { Significance } \\
\text { of difference }\end{array}$ \\
\hline Control & 11 & $<0.001$ & 51 & $n<0.000$ & 112 & $n<0.001$ \\
\hline DU & $381\}$ & $p<0.01$ & 514 & $p<0.01$ & $906\}$ & $\mathrm{p}<0.01$ \\
\hline HSV & $45)$ & $\mathrm{p}<0.0001$ & $86)$ & $\mathrm{p}<0.0001$ & 196 & $\mathrm{p}<0.0001$ \\
\hline PG & 4880 & $p<0.01$ & $8451\}$ & $\mathrm{p}<0.0001$ & $12464\}$ & $\mathrm{p}<0.01$ \\
\hline $\mathrm{TV}+\mathrm{P}$ & 454 ) & NS & 507 & $p<0.001$ & 1298 & $\mathrm{p}<0.01$ \\
\hline $\begin{array}{l}\text { TV+GJ } \\
\text { HSV vs control } \\
\text { HSV vs TV+P } \\
\text { HSV vs TV+GJ } \\
\text { PG } v s \text { DU } \\
\text { PG } v s \text { TV + GJ }\end{array}$ & \begin{tabular}{l}
\multicolumn{1}{c}{424} \\
$p<0.05$ \\
$p<0.01$ \\
$p<0.01$ \\
$p<0.001$ \\
$p<0.01$
\end{tabular} & & $\begin{array}{l}3647 \\
N S \\
p<0.05 \\
p<0.0001 \\
p<0.0001 \\
p<0.05\end{array}$ & & $\begin{array}{l}\quad 6986 \\
N S \\
p<0 \cdot 05 \\
p<0 \cdot 0001 \\
p<0 \cdot 0001 \\
p<0.05\end{array}$ & \\
\hline
\end{tabular}

Mean fasting, post-prandial, and peak values for each group of patients. The standard errors of the means are shown in Figs. 1 and 2. 


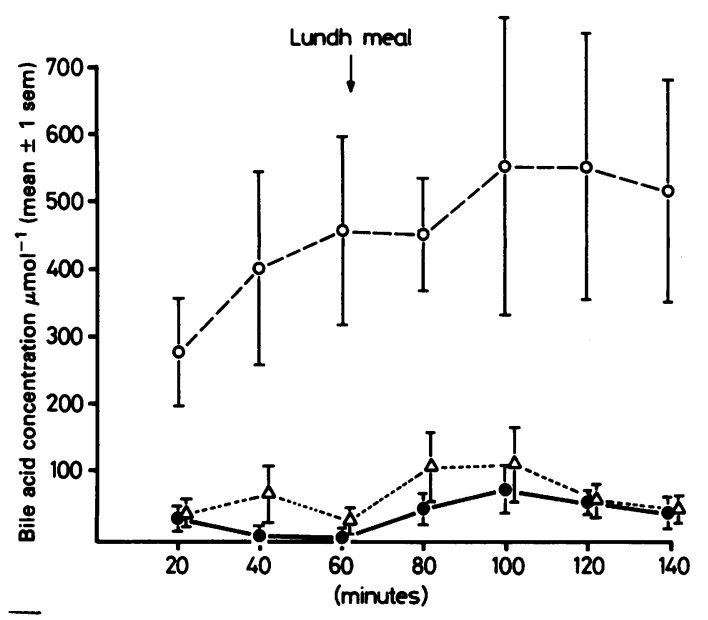

Fig. 1 Bile acid concentrations in the stomach in the fasting state and after a Lundh test meal, in nine normal subjects (control) $(\bullet), 16$ preoperative duodenal ulcer patients $(0)$, and 14 patients after highly selective vagotomy $(\Delta)$.

concentrations were significantly lower than those in duodenal ulcer patients (Fig. 1, Table 2). Postprandial and peak bile acid concentrations after highly selective vagotomy were similar to those in normal controls (Fig. 1), but in the fasting state bile acid concentrations of highly selective vagotomy patients were higher than in controls. Bile acid

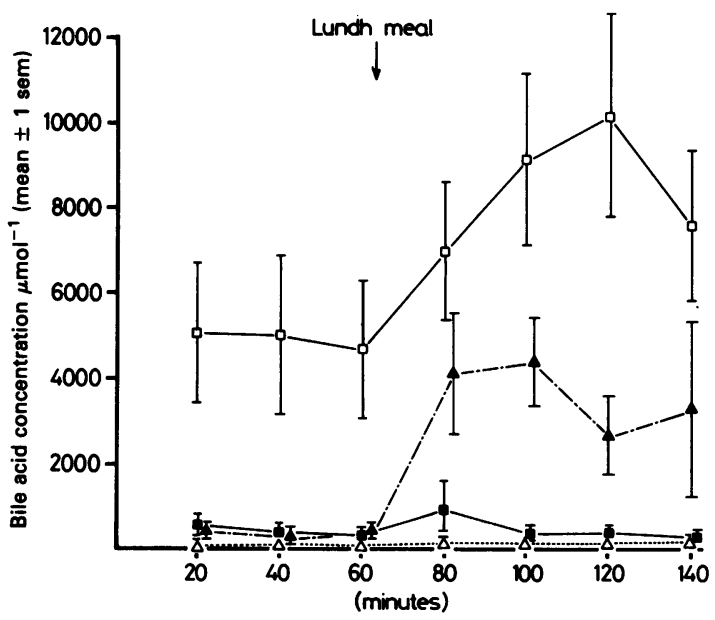

Fig. 2 Bile acid concentrations in the stomach in the fasting state and after a Lundh test meal, in 14 duodenal ulcer patients treated by highly selective vagotomy $(\Delta), 11$ by Polya partial gastrectomy (), nine by truncal vagotomy and pyloroplasty (ם), and eight by truncal vagotomy and gastrojejunostomy $(\mathbf{\Delta})$. Note change in scale from Fig. 1. concentrations in the stomach were significantly less after highly selective vagotomy than after truncal vagotomy and pyloroplasty or truncal vagotomy and gastrojejunostomy.

After Polya partial gastrectomy fasting, postprandial, and peak bile acid concentrations in the stomach were significantly greater than those of controls and duodenal ulcer patients before operation, and also significantly greater than those in patients treated by highly selective vagotomy. Bile acid concentrations in the stomach after Polya partial gastrectomy were significantly greater than those after truncal vagotomy and pyloroplasty and truncal vagotomy and gastrojejunostomy. Bile acid concentrations in the stomach of fasting patients were relatively low after truncal vagotomy and pyloroplasty and truncal vagotomy and gastrojejunostomy and high after Polya partial gastrectomy. After the meal, bile acid concentrations were highest after Polya partial gastrectomy, very high after truncal vagotomy and gastrojejunostomy, and high after truncal vagotomy and pyloroplasty. Duodenogastric reflux was much less after truncal vagotomy and pyloroplasty than after truncal vagotomy and gastrojejunostomy or Polya partial gastrectomy (Fig. 2).

\section{LYSOLECITHIN CONCENTRATIONS IN STOMACH}

Lysolecithin concentrations in the stomach in the six groups of patients are shown in Figs. 3 and 4 and in Table 3.

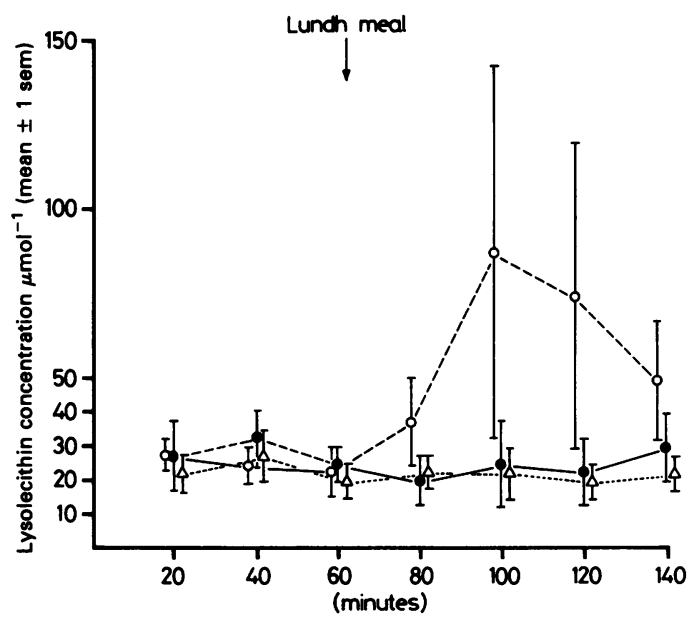

Fig. 3 Lysolecithin concentrations in the stomach in the fasting state and after a Lundh test meal, in nine normal subjects (control) (๑), 16 preoperative duodenal ulcer patients ( $(\circ)$, and 14 patients after highly selective vagotomy $(\triangle)$. 
Table 3 Lysolecithin concentrations $\left(\mu \mathrm{moll}^{-1}\right)$

\begin{tabular}{|c|c|c|c|c|c|c|}
\hline Group & Fasting & $\begin{array}{l}\text { Significance } \\
\text { of difference }\end{array}$ & $\begin{array}{l}\text { Post- } \\
\text { prandial }\end{array}$ & $\begin{array}{l}\text { Significance } \\
\text { of difference }\end{array}$ & Peak & $\begin{array}{l}\text { Significance } \\
\text { of difference }\end{array}$ \\
\hline Control & 29 & NS & $22)$ & NS & 47 & NS \\
\hline DU & $25] J$ & NS & 627 & & $102\}$ & NS \\
\hline HSV & $22)$ & & $22\}$ & $\mathrm{p}<0.0001$ & 42) & \\
\hline PG & $270\}$ & $p<0.01$ & 627 & $\mathrm{p}<0.001$ & $1140\}$ & $\mathrm{p}<0.001$ \\
\hline$T V+P$ & $30)$ & NS & 45 & $\mathrm{p}<0.01$ & $90)$ & $\mathrm{p}<0.01$ \\
\hline $\begin{array}{l}\text { TV+GJ } \\
\text { HSV vs TV+GJ } \\
\text { PG vs control } \\
\text { PG vs DU } \\
\text { PG vs TV+GJ }\end{array}$ & $\begin{array}{l}22 J \\
N S \\
p<0.01 \\
p<0.001 \\
p<0.01\end{array}$ & & $\begin{array}{l}282 \int \\
p<0.001 \\
p<0.001 \\
p<0.0001 \\
p<0.05\end{array}$ & & $\begin{array}{l}\text { 605 } \\
p<0.001 \\
p<0.0001 \\
p<0.0001 \\
p<0.05\end{array}$ & \\
\hline
\end{tabular}

Mean fasting, post-prandial, and peak values for each group of patients. Standard errors are shown in Figs. 3 and 4.

Both in the fasting state and after the meal, lysolecithin concentrations in highly selective vagotomy patients were very similar to those in normal subjects (Fig. 3 ).

In duodenal ulcer patierts before operation, lysolecithin concentrations in the fasting state were similar to those of normal subjects and highly selective vagotomy patients, but post-prandial and peak levels were more than double those in these two groups (Fig. 3, Table 3).

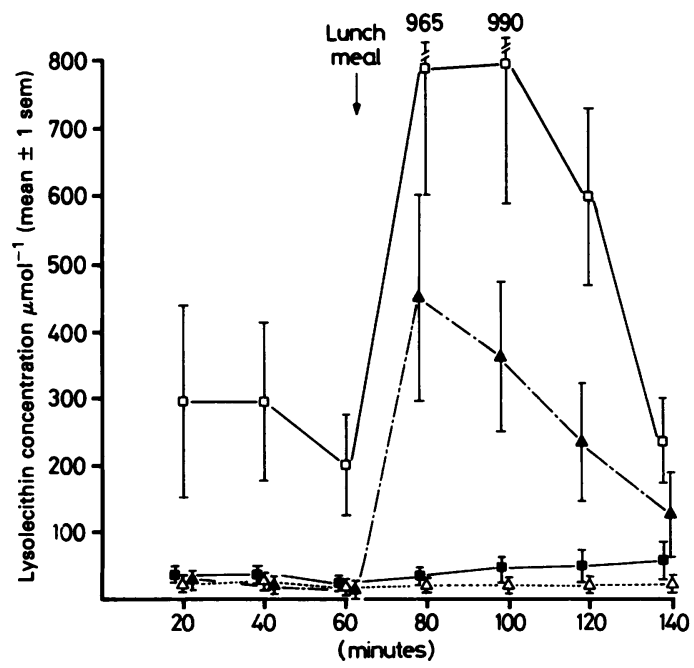

Fig. 4 Lysolecithin concentrations in the stomach in the fasting state and after a Lundh test meal, in 14 patients after highly selective vagotomy $(\triangle), 11$ Polya partial gastrectomy (ㅁ), nine truncal vagotomy and pyloroplasty (a), and eight truncal vagotomy and gastrojejunostomy $(\Delta)$.
When the four postoperative groups of patients are considered (Fig. 4), lysolecithin concentrations were low in the fasting state in the highly selective vagotomy, truncal vagotomy and pyloroplasty, and truncal vagotomy and gastrojejunostomy groups, and no significant differences were found between these groups. The fasting lysolecithin concentrations in these three groups of patients were all significantly lower than the fasting lysolecithin concentrations in the Polya partial gastrectomy group.

After the meal, lysolecithin concentrations remained relatively low after highly selective vagotomy and truncal vagotomy and pyloroplasty, but were greatly and significantly raised after both Polya partial gastrectomy and truncal vagotomy and gastrojejunostomy (Fig. 4).

After Polya partial gastrectomy lysolecithin concentrations (fasting, post-prandial, and peak) were all significantly greater than lysolecithin concentrations after both truncal vagotomy and pyloroplasty and truncal vagotomy and gastrojejunostomy.

\section{Discussion}

The method used to obtain samples of gastric content could be criticised on the grounds that the presence of a nasogastric tube may produce nausea and, in itself, influence duodenogastric reflux. The same conditions prevailed, however, in all subjects and the differences observed between groups were in the main so great that it seems unlikely that the presence of the tube had much influence on the results. Manifestly, the nasogastric tube did not cause much reflux in the control or in the highly selective vagotomy groups. The use of radioisotopes and functional scintigraphy ${ }^{21}$ has recently 
been introduced to demonstrate duodenogastric reflux of bile. Such a technique, however, does not at present permit accurate measurement of reflux and its use is thus complementary to the method that we used, rather than a substitute for it.

The findings of very low bile acid concentrations in the stomach in the control group are in agreement with the findings of Rhodes $e t a l^{22}$ and Fisher and Cohen. ${ }^{23}$ They again show the value of a normal antropyloroduodenal segment in preventing reflux of 'bile' into the stomach. ${ }^{24}$ The preoperative duodenal ulcer patients had significantly higher bile acid concentrations in the stomach than the controls, both in the fasting state and after a meal. These results confirm, and give quantitative expression to, the previous observations of Capper and his colleagues $^{25}$ that patients with duodenal ulcer show evidence of duodenogastric reflux more often than control subjects.

After highly selective vagotomy, relatively low concentrations of bile acid were found in the stomach, only the fasting values being significantly greater than those of normal subjects. All three values of bile acid concentration (fasting, postprandial, and peak) were significantly lower after highly selective vagotomy than in duodenal ulcer patients before operation (Table 2), and, as the two group of patients were well matched, the difference is almost certainly a real one. This finding is at first sight surprising and pre and postoperative studies on the same patients will be required to confirm this point.

The mechanism of duodenogastric reflux is not fully understood, but it may involve abnormalities of motility and pressure in the antropyloroduodenal complex. ${ }^{23}$ Pressure increases in the pyloric sphincter of normal people on response to hormonal stimulation by secretin and cholecystokinin, but there is no response in patients with gastric ulcer. Similarly, duodenal acidification reduces duodenogastric reflux by increasing pyloric sphincter pressure in normal people, but in patients with gastric ulcer it produces little or no increase in pressure. These findings suggest that dysfunction of the pyloric sphincter may be responsible, in whole or in part, for increased reflux of duodenal content into the stomach. In patients with duodenal ulcer, the presence of the ulcer itself just beyond the pylorus could be responsible for abnormal function of the pylorus. Presumably the normal pressure gradient across the antropyloroduodenal complex is altered because of loss of normal pyloric function. Entry of chyme into the duodenum not only stimulates the secretion of bile but also increases duodenal motility and reduces antral motility. ${ }^{26}$ Thus increased pressure in the duodenum and decreased pressure in the antrum, in the presence of dysfunction of the pylorus, may create suitable conditions for duodenal content to enter the stomach. This may explain the similar findings for bile acid and lysolecithin concentrations in the preoperative duodenal ulcer and truncal vagotomy and pyloroplasty groups.

Though many patients with duodenal ulcer probably have some dysfunction of the pylorus, treatment by highly selective vagotomy will at least preserve whatever normal function the antropyloroduodenal segment still possesses, because the pylorus is neither destroyed nor by-passed and the motor innvervation of the antropyloroduodenal complex is preserved. ${ }^{11}$ In addition, highly selective vagotomy may actually improve the function of the pylorus by curing the ulcer and thereby diminishing oedema, muscular spasm, and mechanical deformity.

We think, however, that the best explanation for the finding of diminished duodenogastric reflux after highly selective vagotomy is to be found in the effects of that operation on gastric smooth muscle and on intragastric pressure. After vagal denervation of the body and fundus of the stomach, vagovagal inhibitory reflexes are destroyed, ${ }^{27}$ leading to impairment of receptive relaxation and accommodation to distension by the muscular walls of the stomach: the altered pressure/volume relationships after ingestion of a meal thus result in higher pressures than normal within the stomach. ${ }^{28}$ This increase in intragastric pressure will tend to prevent reflux from the duodenum into the stomach, and it has also been shown to increase the rate of gastric emptying of liquids, ${ }^{29}$ which will itself discourage reflux.

Thus, through its effect on gastric pressure/ volume relationships, by preservation of an intact antropyloroduodenal segment, and, perhaps, by curing the ulcer itself, highly selective vagotomy keeps 'bile' out of the stomach.

The results of the studies on lysolecithin suggest that lysolecithin concentrations in the stomach after highly selective vagotomy are normal. Postprandial levels of lysolecithin in duodenal ulcer patients before operation were nearly three times those in normal subjects. Perhaps because of the wide range of values recorded, however, there was no statistically significant difference between the two groups.

The effectiveness of highly selective vagotomy as an anti-reflux operation is apparent when it is compared with Polya partial gastrectomy, truncal vagotomy and pyloroplasty, and truncal vagotomy and gastrojejunostomy, all of which are operations that either remove the pylorus or interfere with its 
functions. The fasting, post-prandial, and peak bile acid concentrations in the stomach after highly selective vagotomy were found to be highly significantly less than after each of these three procedures. Not only was the degree of reflux much less after highly selective vagotomy, but the duration of exposure of the gastric mucosa to increased concentrations of 'bile' was much longer after these other operations than after highly selective vagotomy. Eighty minutes after the ingestion of the meal, concentrations of bile in the stomach remained high after both partial gastrectomy and truncal vagotomy and gastrojejunostomy. The results of the lysolecithin estimations showed a pattern similar to the results of the bile acid estimations. The highest concentrations of lysolecithin in the stomach were found after partial gastrectomy and truncal vagotomy and gastrojejunostomy, especially after the meal. After truncal vagotomy and pyloroplasty the post-prandial and peak lysolecithin concentrations, though not significantly higher than after highly selective vagotomy, were double those found after highly selective vagotomy and remained so for at least 80 minutes after the meal.

These findings suggest that removal or bypass of the pylorus, with gastrojejunal anastomosis, as in Polya partial gastrectomy and truncal vagotomy and gastrojejunostomy, allows much more duodenal content to enter the stomach than occurs after pyloroplasty, which produces less alteration of the normal anatomy. After partial gastrectomy, concentrations of bile acids and lysolecithin in the stomach were significantly higher than after truncal vagotomy and gastrojejunostomy. This could be due to the inhibitory effect of truncal vagotomy on biliary and pancreatic secretion. ${ }^{30-32}$ Again, refluxing duodenal content might be diluted to a greater extent by gastric secretions after truncal vagotomy and gastrojejunostomy than after partial gastrectomy. Finally, the degree of reflux may be related to some extent to the size of the stoma, which may be somewhat larger, on average, after partial gastrectomy than after truncal vagotomy and gastrojejunostomy.

Whatever factor or combination of factors may be involved in the increased duodenogastric reflux after partial gastrectomy and truncal vagotomy with a drainage procedure, it is unlikely that the greater length of follow-up of the patients who underwent these procedures was responsible for the increased reflux. If reflux is going to occur it will probably be manifest soon after the operation, and all the patients studied had been operated upon more than one year before.

Reports from many centres have highlighted the importance of keeping 'bile' out of the stomach. The presence of bile acids and lysolecithin in the stomach has been shown to increase the movement of hydrogen ions out of the lumen of the stomach into the mucosa ${ }^{4}{ }^{33-35}$ where they cause histamine to be released and gastritis to develop. Lysolecithin is formed in the duodenum when phospholipase $A$ of pancreatic juice hydrolyses the lecithin in bile, the reaction being activated by bile acids and trypsin. The gastritis that is produced by exposure of the gastric mucosa to the combined contents of the duodenum has been shown in dogs to be considerably worse than the gastritis that is caused by pure pancreatic juice alone or by pure bile alone. ${ }^{3637}$ It was for that reason that we measured both bile acids and lysolecithin. In a separate report the relationship between gastritis and the reflux of bile acids and lysolecithin is being examined.

In man, regurgitation of 'bile' into the stomach may lead to nausea and bilious vomiting, but of greater importance is the prolonged irritation of the gastric mucosa, which produces chronic superficial gastritis and eventually chronic atrophic gastritis. ${ }^{38}$ These changes in the gastric mucosa produce a syndrome of 'bile reflux gastritis' or 'alkaline reflux gastritis' in a proportion of patients. The syndrome is characterised by persistent epigastric pain, vomiting, anorexia, and loss of weight.

In the longer term, prolonged contact of 'bile' with the gastric mucosa may well be a factor in the development of gastric carcinoma. Gastritis progresses, with the development of intestinal metaplasia, which some authors believe to be a pre-cancerous lesion, ${ }^{38}$ though others doubt whether the presence of such metaplasia is of value as a predictor of cancer. ${ }^{39}$ Many reports have shown that the incidence of gastric 'stump' carcinoma is significantly increased more than 15 years after Billroth 1 partial gastrectomy, Polya partial gastrectomy, or even gastrojejunostomy alone. ${ }^{8-1040}$ The carcinomatous change usually develops close to the stoma, where the damage to the gastric mucosa is greatest, a fact that strongly suggests that 'bile' reflux may be an important factor in the genesis of the condition. When Schrumpf and his colleagues ${ }^{10}$ endoscoped 108 asymptomatic patients who had undergone partial gastrectomy 20 to 25 years before, they found that four of them had infiltrating gastric carcinoma and another three had carcinoma-in-situ: all but one of the remaining patients had either severe chronic gastritis, intestinal metaplasia, or dysplasia. Thus it seems likely that loss of the pylorus and the excessive duodenogastric reflux that follows exposes the patient to a considerable risk of developing gastric carcinoma in the long term.

The severity of the gastritis that develops is 
proportional to the amount of duodenal content that refluxes and to the duration of the exposure of the gastric mucosa to the irritant. ${ }^{36}$ The results of this study suggest that when highly selective vagotomy is used in the treatment of duodenal ulcer, both the quantity of bile in the stomach and the length of time that it is in contact with the gastric mucosa are signficantly less than after other operations that destroy or bypass the pylorus. Meticulous, longterm studies are now needed to test our hypothesis that the reduced duodenogastric reflux seen after highly selective vagotomy benefits the patient in terms both of fewer symptoms of gastritis and a lower risk of gastric carcinoma.

\section{References}

1 Lawson $\mathrm{HH}$. The role of the pyloric antrum and Hofmeister valve in the development of the chronic gastric mucosal reaction. Br J Surg 1976; 63: 592-5.

2 du Plessis DJ. Gastric mucosal changes after resection of the stomach. $S$ Afr Med J 1962; 36: 471-8.

3 Lawson $\mathrm{HH}$. Effect of duodenal contents on the gastric mucosa under experimental conditions. Lancet 1964; 1: 469-72.

4 Orchard R, Reynolds K, Fox B, Andrews R, Parkins RA, Johnson AG. Effect of lysolecithin on gastric mucosal structure and potential difference. Gut 1977; 18: $457-61$.

5 Scudamore HH, Eckstam EE, Fencil WJ, Jaramillo CA. Bile reflux gastritis. Am J Gastroenterol 1973; 60: 9-22.

6 Drapanas T, Bethea M. Reflux gastritis following gastric surgery. Ann Surg 1974; 179: 618-27.

7 Keighley MRB, Asquith P, Alexander-Williams J. Duodenogastric reflux: A cause of gastric mucosal hyperaemia and symptoms after operations for peptic ulceration. Gut 1975; 16: 28-32.

8 Stalsberg H, Taksdal S. Stomach cancer following gastric surgery for benign conditions. Lancet 1971; 2: 1175-7.

9 Domellöf L, Eriksson S, Janunger K-G. Late precancerous changes and carcinoma of the gastric stump after Billroth 1 resection. Am J Surg 1976; 137: 26-31.

10 Schrumpf E, Stadaas J, Myren J, Serck-Hanssen A, Aune S, Osnes M. Mucosal changes in the gastric stump 20-25 years after partial gastrectomy. Lancet 1977; 2: 467-9.

11 Johnston D, Wilkinson AR. Highly selective vagotomy without a drainage procedure in the treatment of duodenal ulcer. Br J Surg 1970; 57: 289-96.

12 Goligher JC, Pulvertaft CN, de Dombal FT, Conyers $\mathrm{JH}$ et al. Five to eight year results of Leeds/York controlled trial of elective surgery for duodenal ulcer. Br Med J 1968; 2: 781-7.

13 Findlay JM, Prescott RJ, Sircus W. Comparative evaluation of water recovery test and fluoroscopic screening in positioning a nasogastric tube during gastric secretory studies. $\mathrm{Br}$ Med J 1972; 4: 458-61.

14 Magee WL, Gallai-Hatchard J, Sanders H. Thompson RHS. The purification and properties of phospholipase A from human pancreas. Biochem $J$ 1962; 83: 17-25.

15 Fausa O, Skalhegg BA. Quantitative determination of bile acids and their conjugates using thin layer chromatography and a purified $3 \propto$-hydroxysteroid dehydrogenase. Scand J Gastroenterol 1974; 9: 249-54.

16 Bligh EG, Dyer WJ. A rapid method of total lipid extraction and purification. Can J Biochem Physiol 1959; 37: 911-7.

17 Nelson GJ. Quantitation, composition and metabolism. In: Blood lipids and lipoproteins. New York: Wiley Interscience, 1972: 55

18 Marinetti GV. Chromatographic separation, identification and analysis of phosphatides. J Lipid Res 1962; 3: 1-20.

19 Fiske $\mathrm{CH}$, Subbarrow Y. Colorimetric determination of phosphorus. J Biol Chem 1935; 66: 375-400.

20 Snedecor GW, Cochran WG. Statistical methods Ames, Iowa: Iowa State University Press, 1967.

21 Mackie CR, Wisbey $M$, Cuschieri A. Milk ${ }^{99} \mathrm{Tc}^{\mathrm{M}} \mathrm{EHIDA}$ test for enterogastric bile reflux. $\mathrm{Br} \mathrm{J}$ Surg 1981; 68: 351.

22 Rhodes J, Barnardo DE, Phillips SF, Rovelstad RA, Hofmann AF. Increased reflux of bile into the stomach in patients with gastric ulcer. Gastroenterology 1969; 57: 241-52.

23 Fisher RS, Cohen S. Pyloric sphincter dysfunction in patients with gastric ulcer. $N$ Engl J Med 1973; 288: 273-6.

24 Keighley MRB, Asquith P, Edwards JAC, AlexanderWilliams $J$. The importance of an innervated and intact antrum and pylorus in preventing postoperative duodenogastric reflux and gastritis. Br J Surg 1975; 62: 845-9.

25 Capper WM, Airth GR, Kilby JO. A test for pyloric regurgitation. Lancet 1966; 2: 621-3.

26 Brink BM, Schlegel JF, Code CF. The pressure profile of the gastroduodenal junction zone in dogs. Gut 1965; 6: $163-71$.

27 Martinson J. Studies on the efferent vagal control of the stomach. Acta Physiol Scand 165; 65: suppl 255: 5-24.

28 Stadass J, Aune S. Intragastric pressure/volume relationship before and after vagotomy. Acta Chir Scand 1970; 136: 611-5.

29 Wilbur BG, Kelly KA. Effect of proximal gastric, complete gastric, and truncal vagotomy on canine gastric electric activity, motility and emptying. Ann Surg 1973; 3: 295-303.

30 Malagelada JR, GO VLW, Summerskill WHJ. Altered pancreatic and biliary function after vagotomy and pyloroplasty. Gastroenterology 1974; 66: 22-7.

31 MacGregor IL, Parent J, Meyer JH. Gastric emptying of liquid meals and pancreatic and biliary secretion after subtotal gastrectomy or truncal vagotomy and pyloroplasty in man. Gastroenterology 1977; 72: 195205.

32 Lavigne ME, Wiley ZD, Martin P et al. A study of 
gastric, pancreatic and biliary secretion, and the rate of gastric emptying following parietal cell vagotomy. Am J Surg 1979; 138: 644-51.

33 Ivey KJ, DenBesten L, Clifton JA. Effect of bile salts on ionic movement across the human gastric mucosa. Gastroenterology 1970; 59: 683-90.

34 Davenport HW. Destruction of the gastric mucosal barrier by detergents and urea. Gastroenterology 1968; 54: $175-81$.

35 Davenport HW. Effect of lysolecithin, digitonin and phospholipase A upon the dog's gastric mucosal barrier. Gastroenterology 1970; 59: 505-9.

36 Lawson HH. The effect of the duodenal contents on the gastric mucosa. S Afr J Surg 1965; 3: 79-92.
37 Dragstedt LR, Woodward ER, Seito T, Isaza J, Rodriguez JR, Samiian R. The question of bile regurgitation as a cause of gastric ulcer. Ann Surg 1971; 174: 548-59.

38 Morson BC, Dawson IMP. Gastrointestinal pathology. Oxford: Blackwell, 1972.

39 Domellöf L, Eriksson S, Janunger K-G. Carcinoma and possible precancerous changes of the gastric stump after Billroth II resection. Gastroenterology 1977; 73: 462-8.

40 Siurala M, Lehtola J, Ihamäki T. Atrophic gastritis and its sequelae. Scand J Gastroenterol 1974; 9: 441-6.

41 Leading Article. After gastrectomy. Br Med J 1981; 282: 1096-7. 